\title{
Gray Area Ethical Leadership in the NCAA: The Ethics of Doing the Wrong Things Right
}

\author{
Michael Sagas \\ University of Florida \\ Brian J. Wigley \\ Shenandoah University
}

\begin{abstract}
The NCAA's operating manuals provide member institutions with hundreds of pages of bylaws that outline how member institutions should operate their athletic programs. Interpretations of these rules can lead to sanctions for student-athletes, coaches, athletic administrators and institutions. Such rule-based systems can potentially lead to the belief that simply following the rules as written equates to right or ethical behavior. In this commentary, we used an ethical leadership framework primarily built on the leadership and management thoughts of Bennis and Nanus (1985) to propose the College Athletics Ethical Leadership Continuum which can be used to assess the behaviors, rules, and decisions made by NCAA membership. Fundamental principles of this conceptual model include holding the student-athlete as the primary stakeholder of college sports activities, and that a critical analysis of the present is necessary to provide leadership for the future. Based on a distinction between doing things right and doing the right thing, the model is applied to four case studies in which NCAA membership policies and actions, or lack thereof, are likely compromising the wellbeing and academic success of student-athletes.
\end{abstract}

Keywords: ethical leadership, Division I, Division III

The rules and bylaws that govern how the National Collegiate Athletic Association (NCAA) operates have evolved in unique and complex ways since the inception of the association over 100 years ago. The manual has also grown in size and scope as is evident from the length of the most recent 2013-14 operating manuals that range from 274 to 351 pages depending on the NCAA division. The operating manuals for each division define requirements for member institutions to be a part of the association, and also identify what members schools can and cannot

\footnotetext{
Sagas is with the Department of Tourism, Recreation and Sport Management and Faculty Athletics Representative, University of Florida, Gainesville, FL. Wigley is with the Byrd School of Business, and Faculty Athletics Representative, Shenandoah University, Winchester, VA. Address author correspondence to Michael Sagas at msagas@ufl.edu.
} 
do when operating their programs related to such things as recruiting, personnel, eligibility, and the playing season for their sports.

At the Division I level, the regulations and bylaws that govern the association are created by the membership of the association though a legislative process that submits proposals for new and revised rules to the Legislative Council, which serves as the primary legislative body of Division I. The Legislative Council is populated by representatives of member institutions including athletic department administrators, Faculty Athletic Representatives, and conference level administrators. Legislation that is approved by the Legislative Council is sent to the NCAA Division I Board of Directors (which is populated by member institution presidents and chancellors) for approval to become effective, unless the legislation is overridden by a five-eighths vote of active members (Davis \& Hairston, 2013). The process in place for proposals to become legislation at the NCAA Division III level is very similar to that of Division I. Changes in legislation, rules, or policies come from either member institutions or conferences, or various standing committees, to the Division III Management Council and then the Division III President's Council. It is also important to note that NCAA staff members are frequently involved with enforcement and interpretation of the rules for the membership along with member institution representatives on various NCAA committees.

Indeed, most of the rules in the three NCAA manuals are necessary to facilitate the common good of the association as a whole, and the solvency and wellbeing of each member institution of the association. For example, these bylaws attempt to protect the safety and well-being of student-athletes (e.g., by mandating that institutions have a concussion management plan) and even prospective studentathletes (e.g., by limiting when and how often prospective student-athletes can be contacted). Several bylaws have also been introduced over the years to facilitate a NCAA governance philosophy of competitive equity (Davis \& Hairston, 2013). Competitive equity essentially amounts to a leveling of the playing field through rules and regulations to allow those that have specific resources, or other sources of competitive advantage, to remain competitive with those that have fewer resources.

Some of rules in the NCAA manual make good sense to most observers, but some also seem to be quite trivial. For example, does the NCAA really need to stipulate to their Division I members that using a limousine or helicopter for transportation during a recruiting visit is not a good idea or that it is acceptable to feed student-athletes fruit, nuts, and bagels during vacation periods? The NCAA Division I working groups that resulted from the Division I Presidential Retreat in August of 2011 were working toward remedying the proliferation of several meaningless or unenforceable regulations. The work of these groups attempted to revise legislation to allow for more autonomy for campuses in doing what they feel is right for their student-athletes, regardless of the impact on association wide competitive equity (Davis \& Hairston, 2013).

Clearly rules are necessary in competitive sport, and the NCAA's ruled-based system is required in an organization with so many stakeholders, sports, levels, and teams. However, the reality is that as time passes new situations have arisen which facilitated new rules, as well as created specific ways to circumvent the existing rules. The use of emerging technologies provides an example. Twenty years ago there was obviously no need for rules to regulate contact via the internet or via text messaging. While some rules are instituted to address new realities associated 
with operating collegiate athletics departments, others are put into place due to the identification of loopholes or "ways around" the current rules that have been discovered and are being used. These loopholes, while not against the letter of the law, may be in violation of the spirit of the rule. Although the NCAA membership appears to work to close loopholes as they become apparent, there can also be instances when an action is likely not a wise thing to do, but since it is not directly addressed in the written rules, doing the act is not considered a rules violation.

Kvalnes and Hemmestad (2010) argue that, "a rule-based approach to ethics can encourage sport practitioners to adopt a loophole mentality that is likely to lead to more rather than less unethical behavior in sport" (p. 57). The case of the National Hockey Leagues' (NHL) "Sean Avery Rule" demonstrates the potential pitfalls of rule-based systems. In a 2008 NHL game between Avery's New York Rangers and the New Jersey Devils, Avery placed himself immediately in front of the opposing goal-keeper to distract him and obstruct his view of the game and specifically the puck. In response to comments critical of his strategy, Avery pointed out - correctly - that he had broken no rule (TSN.CA Staff, 2008). Although the next day the NHL added a rule which banned his tactic, the point to be taken from this example is that it seems impossible to include every possible transgression or loophole in a written set of rules.

Critics have argued that highly formalized organizations with stringent and complex rules create environments in which the rules themselves dominate decisionmaking. Gough (1994) contends that practical and ethical thought is hindered by systems based on legislative rules, creating an environment in which rules and ethics are inseparable. Such bureaucratic systems result in the mindset that "if it is legal, it is right" (Gough, 1994; Michael, 2006), and this may decrease the possibility of athletic administrators considering their own personal moralities, or considering specific circumstances when rendering judgment. Kihl (2007) surveyed NCAA Division I compliance officers to access the practical morality among athletic administrators. One significant finding of Kihl's work was that individuals, in the light of conflict between personal conceptualizations of what is right under the structured NCAA's rule-based system, often resorted to "hiding behind the rules" (p. 296). By interpreting the rules in a strict, 'by-the-book' manner, individual responsibility for determining right or moral conduct is diminished if not eliminated. We contend that the NCAA's legalistic environment may lead stakeholders to choose strict adherence to the written rules of the membership, which relieves them of the more arduous and personal deliberations about what the right decision may be in a given circumstance.

From a basic ethical perspective which dictates that what is ethical is right, good, and just and what is unethical is considered wrong, bad, or unjust (Kant \& Paton, 2009), we believe that most sensible observers would contend that when a member institution conducts an activity that is impermissible according to the NCAA bylaws, it would be wrong (i.e., unethical). Further, when NCAA member institutions violate state or federal laws, it is also quite clear that they conducted themselves in an unethical way. These ethical situations can be considered black and white. However, we feel that there is a large "gray area" in the rules that are created and that ultimately govern the NCAA. That is, it is much less clear from an ethical lens if not violating a rule clearly suggests that something is right or good (i.e., ethical). In other words, is the NCAA bylaw really the moral minimum in which to base one's actions as ethical or unethical? Furthermore, what is most 
indistinguishable in our opinion is if something can be deemed unethical as a result of a clearly misguided and unfair NCAA rule that is in the bylaws, or one that is altogether absent from the NCAA rules. Since the membership controls the bylaws and the NCAA controls the enforcement and interpretation of the bylaws, the power to adopt rules that are right, good, and just appears to be feasible and completely in the control of these actors.

The purpose of this paper is to provide a conceptual framework in which to view the ethical leadership (or lack thereof) exhibited by NCAA Division I and Division III member institutions related to the "gray areas" of ethical decision making. Indeed, breaking an NCAA bylaw is not right and subsequently likely an unethical behavior. But is the adoption of a poor or misguided rule, and the omission and avoidance of other rules that can address real problems for key stakeholders, namely student-athletes, also unethical?

We provide an analysis of four distinct cases (two from Division I and two from Division III) in which we feel that the avoidance of the adoption of a rule dictates behavior that is wrong and potentially unethical, especially when considering the well-being, development, and academic success of student-athletes. Through these cases we contend that the reliance of NCAA bylaws as a moral minimum has led to many NCAA leaders maintaining their ethical high ground by doing some wrong things very well (i.e., without a violation of NCAA rules), but that they are failing to do the right thing by following a misguided rule, and failing to address and adopt others.

\section{College Athletics Ethical Leadership Continuum Model}

Many ethical decision making models exist and provide managers with excellent perspectives in which to view their behaviors from various ethical points of view. Literature related to ethical leadership encourages leaders to "do the right thing" (Bennis \& Nanus, 1985; Garza Mitchell, 2012) which seems both obvious and simplistic. Yet, defining what is "right" or "ethical" can be difficult.

Numerous scholars (Eddy, 2010; Groves \& Larocca, 2011; Kanungo, 2001; Preskill \& Brookfield, 2009) have made clear the relationship between leadership style and ethical perspective. Traditionally, authoritarian and transactional leadership models were considered most salient to discussions of organizations and ethical leadership. These models tend to focus on the organization and its rules, rather than individuals within the organization and external communities. Although these approaches certainly have merit, current literature related to leadership focuses more so on deontological ethical values, as the trend is to emphasize collaboration and the notion of a social good (Garza Mitchell, 2012). The current focus on deontology-based leadership emphasizes a focus on individuals within organizations and external communities. The foundation of deontological ethics is what actors "ought" to do. In a post-Enron era of leadership marked by a call for transparency and increasingly dramatic change, leaders must be aware of the ethical foundations and implications of their leadership behaviors and styles so that they are able to make clear to stakeholders why and how decisions were made (Garza Mitchell, 2012). Deontological theories focus on duty, moral obligations and the "intentions of the decision maker and the means chosen to accomplish a task" (Armstrong \& Muenjohn, 2008, p. 25). Given the emphasis on the obligations and 
duty the NCAA and its member institutions have in regards to the student-athlete as the primary stakeholder in the proposed model, this ethical theory seems most salient. In addition, considering that, as noted above, all circumstances and possible dilemmas cannot be accounted for in any set of written rules, the fact that intentions and means are considered in deontological ethics makes this theory most salient for the current proposal and in collegiate athletics in general.

One potential roadblock to achieving consistent ethical decision-making and leadership in collegiate athletics could be the lack of understanding by leaders that the issues or conflicts at hand are indeed ethical in nature. Research in related fields has demonstrated that leaders often marginalize the importance of ethics in the decisions they are charged with making. For example, in a study of high school principals, Campbell (1992) found that these educational leaders believed that their daily challenges were strategic, professional, administrative, political or procedural rather than ethically based. Other studies have also noted that ethics is not likely to be considered as a significant focus of work in leadership positions (Campbell, 1997; Mahoney, 2006; Starratt, 2004). In these and other studies, ethics was found to be viewed of secondary importance in terms of its relevance to authority (Sergiovanni, 1992) or decision-making (Shapiro \& Stefkovich, 2005).

The framework we have developed to analyze the gray areas of ethical leadership in the NCAA integrates management and leadership thought with a deontological ethics lens. Our ethical framework is primarily built on the leadership and management thoughts of Bennis and Nanus (1985) as a frame for how leaders governing NCAA sports "ought" to behave. These authors contend that managers are people who do things right but that leaders are people who do the right thing. Bennis later expanded on this notion that distinguishes leaders from managers by suggesting "I often observe people in top positions doing the wrong thing well" and that "they do not pay enough attention to doing the right thing, while they pay too much attention to doing things right" (Bennis, 1989, p. 18). A recent commentary advanced by Gillen (2012) expanded on this work suggesting that doing things right is not enough in providing innovative leadership. Addressing the topic of military behavior, Gillen suggests that doing things right is primarily focused on managing the present and that doing the right thing is essentially concerned with selectively abandoning the past, while creating the future. Fundamentally, Gillen's framework suggests that managing the present is tactically focused on compliance, the status quo, and managing performance and that creating the future is strategic and critical in nature, and focused on growth and innovation.

We expand on these perspectives and suggest that NCAA actors who only do things right, while avoiding or rejecting the difficult critical analysis required to ascertain the right things to do, are failing to provide innovative and ethical leadership for the association. Given the continually elevated expectations, visibility, and resources available to NCAA institutions, a continuous selective abandoning of the past in strategic ways, while subsequently creating the future, is absolutely essential to providing ethical leadership. Doing things right is not enough, and doing the wrong things right is clear ethical failure. Doing the right thing is the moral minimum in which to assess ethical behavior and leadership. And, in our opinion, the primary stakeholders in which to consider what is right or wrong should be the NCAA student-athletes, and not coaches, an athletic department or program, a professional league, or media conglomerate. 
This framework is depicted in Figure 1 as the College Athletics Ethical Leadership Continuum. We contend that ethical leadership can be conceived on a continuum in which a moral minimum establishes if a decision is right or wrong. As suggested in the model, we feel that the current moral minimum is likely just above behaviors that are clearly illegal according to federal or state laws, or NCAA, conference, and institutional rules. However, we would like to suggest that the moral minimum be raised to a much higher standard than just above the idea of doing things right. That is, we suggest that ethical leadership in the NCAA is only exhibited by minimally doing the right thing for student-athletes, first and foremost. This higher ethical ground considers the student-athlete as the primary stakeholder and applies critical analysis to present practices to allow for a selective abandonment of past practices, to lead a moral future of college sports. These two ethical positions are connected with what we consider to be the current gray area of ethical decision-making in college athletics, one in which most actors are concerned with serving multiple stakeholders who are often in direct opposition to the development, well-being, and academic success of student-athletes. Examples of stakeholders whose interests could potentially divert the focus of collegiate athletics away from the student-athlete include but are not limited to: media conglomerates, sporting goods companies, advertising and sponsorship entities, and professional leagues. This position that accepts multiple stakeholders oftentimes accepts the

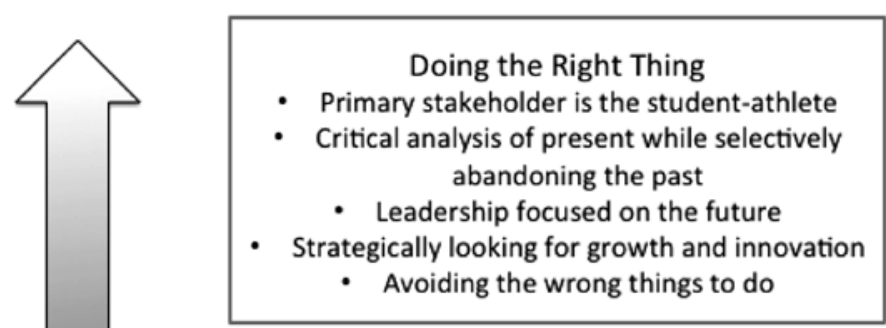

Proposed Moral Minimum

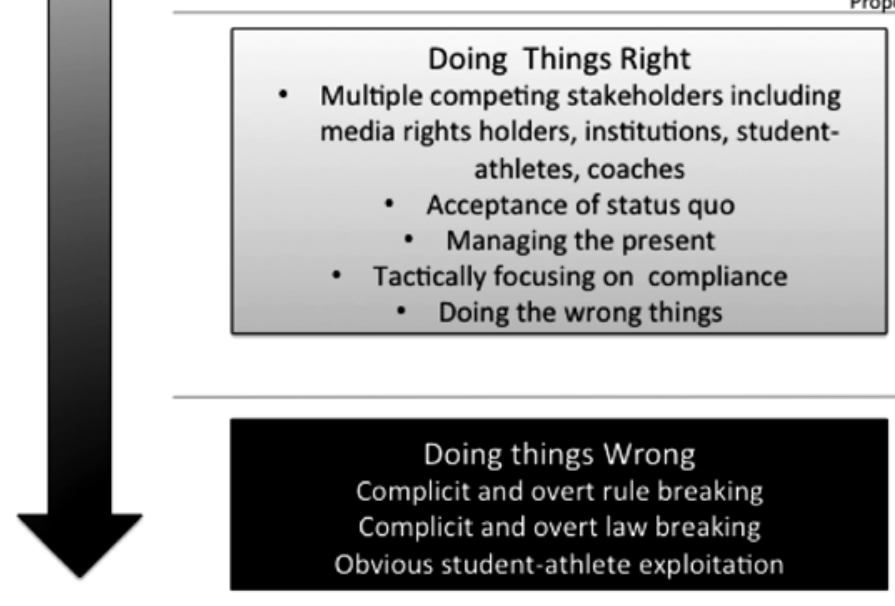

Figure 1 - College Athletics Ethical Leadership Continuum

Current Moral Minimum 
status quo for student-athletes, and rejects the establishment of rules that could protect, reward, and elevate them. Compliance is critically important in this gray area and thus things are often done right (i.e., by the rules), but we believe that there are several instances in which actors are doing the wrong things altogether. Thus, we believe that as a collective the NCAA membership and leadership are not achieving a moral minimum that is necessary to progressively evolve as an association in the best interests of student-athletes.

Although perhaps obvious to some, recent developments in collegiate athletics make necessary a statement or rationale for the emphasis of the student-athlete as primary stakeholder. The basis for and the foundation of the NCAA is the concept of the student-athlete. As quoted from the NCAA strategic plan, the Core Purpose and Values statement of the organization reads:

Our purpose is to govern competition in a fair, safe, equitable and sportsmanlike manner, and to integrate intercollegiate athletics into higher education so that the educational experience of the student-athlete is paramount (NCAA, 2014a).

Furthermore, it is clear from the messages that the current President of the NCAA sends regarding the mission and values of the organization that the studentathlete experience is the primary goal of the work of the association. For example, this statement from President Mark Emmert's "About" page on the NCAA Website clearly spells out the priority that should be given to student-athletes:

No matter the size of our stadiums, the number of scholarships we offer or the number of zeros in our bottom line, we share the same goal: to promote student-athlete success in the classroom, on the field and in life. Decisions that support that goal align us with the mission of higher education - where the student is always the priority (NCAA, 2014b).

Nowhere to be found in this fundamental charge or the core values of the NCAA are media companies, corporate sponsors, or other economically motivated stakeholders. It is our contention that college athletics at its finest occurs when the student-athlete is paramount.

\section{Case Analysis}

To demonstrate the application of this ethical leadership model, four cases are presented and analyzed. Each case focuses on the gray areas of ethical leadership and represent circumstances at both Division I and Division III levels.

\section{NCAA Division I Cases}

The work of several of the NCAA Division I working groups that evolved from the 2011 NCAA Presidential Retreat made some excellent progress toward abandoning the past and refocusing the future with a focus on student-athletes. As noted by the NCAA in summarizing the complex process, "The goal of deregulation is to protect and enhance the student-athlete experience, shift the regulatory focus from competitive equity to fair competition and allow schools to use the natural advantages of geography, a talented student-athlete or deeper pockets" (NCAA, 
2013, p. 1). However, procedural and communication mishaps, attempted and successful membership voting overrides, and overall NCAA governance issues halted much of the significant progress made by these groups. As suggested by the two cases below, we feel that several member institutions' voting behaviors and statements clearly failed to raise the moral minimum to above the status quo for NCAA student-athletes.

Multiyear Scholarships. In 1973, the NCAA membership adopted legislation that limited institutions to awarding a maximum athletic scholarship, which includes tuition, required fees, room, board, and books, to one calendar year (Davis \& Hairston, 2013). In the fall of 2011, the NCAA Board of Directors adopted new legislation that permitted institutions to award multiyear athletic scholarships for a maximum of five years (Davis \& Hairston, 2013; Hosick, 2012). The new bylaw did not require that institutions award multiyear scholarships but did give them the option to do so.

We feel that this legislation clearly protects student-athletes from coaches that may use their discretion in renewing a one-year scholarship offer to run athletes off of teams after a year or two to make room for better players. Furthermore, the one-year scholarship also allowed institutions to not renew athletic scholarships to student-athletes that were unable to participate in their sport because of an athletic related injury. In essence, colleges and universities had unlimited discretion to renew or not renew an athletic scholarship, which clearly provided the balance of power in the player-coach relationship to the coach, as student-athletes are often defenseless if their scholarship offer is not renewed at the end of their one-year agreement (Segrest, 2011).

We contend that ethical leadership was not exhibited in relation to this important piece of legislation in two specific ways. First, the legislation was narrowly upheld, by just two votes, in an override vote of the membership that occurred in February of 2012. A total of 205 institutions voted against the legislation, but 207 of the 330 votes that were submitted by institutions and conferences were needed to reach a five-eighths majority. In media accounts reporting on the override attempt, it was suggested that several of the opponents of the legislation were much more interested in retaining competitive equity related to recruiting than they were studentathlete welfare. For example, Boise State, which voted in support of the override, suggested that the multiyear scholarship would be a recruiting disaster and that it would pit wealthy schools against those with less financial means. Further, it also suggested there are never guarantees that student-athletes will fit in a program and thus assuring them a commitment beyond one year is not a good strategic practice (Associated Press, 2011).

However, what was most disturbing about the override votes were not the motivations offered for objecting to the legislation; it was the roll-call report which indicated that several schools with significant wealth and means were not interested in guaranteeing the financial welfare of their student athletes, despite their budgetary capacity to do so. While a majority of the override votes were submitted by programs with smaller football programs that compete at the NCAA Football Championship Subdivision level, several well-resourced Football Bowl Subdivision (FBS) institutions also voted in support to the override (e.g., Florida State University, University of Texas, University of Arizona, University of California-Berkeley, and University of Southern California). 
Furthermore, it was quite interesting that Yale University, which does not even offer athletics related financial aid, also voted in support of the override (Wolverton, 2013).

Secondly, we feel that unethical leadership has continued to be exhibited by several institutions even now that coaches are empowered to offer multiyear scholarships. As Dent (2013) notes, since the adoption of the rule in 2011, multiyear scholarships are still fairly rare. Dent's research, obtained through open records requests, suggested that of the 82 institutions analyzed at the Division I FBS level, only 16 have offered more than 10 multiyear scholarships, 32 have offered at least one but less than 10, and 34 had not offered any at the time of his analysis in February of 2013. The list of institutions that have failed to provide a multiyear commitment to their athletes included several well-resourced institutions like the University of Oregon, the University of Texas, Clemson, and Texas A\&M. However, several institutions have clearly exhibited ethical leadership on this issue by awarding multiyear scholarships to their athletes across all sports, including Fresno State $(N=316)$, Illinois $(N=293)$, and Purdue $(N=$ 122). When assessed against the ethical leadership model we are proposing, it is our contention that the well-resourced institutions from the larger FBS conferences were more interested in preserving the status-quo than leadership that is looking to grow and innovate the treatment of student-athletes. Furthermore, most institutions have yet to use the multiyear scholarship to any great degree, which demonstrates that they are more interested in preserving the power of the institution and coach as the primary stakeholders, and are not considering the student-athlete as the principal beneficiary of the opportunity to receive a longterm commitment.

The \$2,000 Miscellaneous Expense Allowance. As indicated, a full financial scholarship for NCAA Division I athletes consists of tuition, required fees, room, board, and books. In late 2011, one of the NCAA working groups, the StudentAthlete Well-Being Working Group, submitted a proposal to the NCAA Board of Directors to allow institutions to provide financial support for student athletes that went above this defined minimum scholarship. This legislation allowed institutions to also provide student-athletes funds to pay for miscellaneous expenses, such as laundry and occasional travel home. The proposed amount of this additional aid was the lesser of an institution's true cost of attendance or \$2,000 (Davis \& Hairston, 2013). The NCAA Board of Directors approved this legislation in their January 2012 Annual Meeting, which allowed schools to immediately offer the additional \$2,000 financial aid in their scholarship offers to student-athletes that were receiving the equivalent of a full grant-in-aid. Thus, student-athletes on partial scholarships were not eligible to receive any of the $\$ 2,000$ allowance (Davis \& Hairston, 2013).

Proponents of this additional aid for athletes suggested that athletic financial aid was artificially restricted to just certain aspects of a student-athletes' cost of attendance in the name of competitive equity. In addition, non-student-athlete students on merit based scholarships regularly receive academic scholarships that cover the true full cost of attendance which can include transportation costs, a personal expense allowance, computer and cell phone expenses, and even a clothing maintenance allowance. The $\$ 2,000$ additional stipend would thus take a step toward covering some, if not all, of these expenses for student-athletes. 
The adopted legislation was suspended by the Board of Directors in December of 2011 after strong opposition and a successful override vote by NCAA Division I membership. Similar to the override votes conducted for and against the multiyear scholarship legislation, the failure to provide ethical leadership in support of student-athlete welfare can be viewed through an analysis of the justifications and the voting roll-call in support of the override. In our view, these institutions did advance some legitimate concerns with regard to gender equity, but also advanced commentary that was much more concerned with preserving their competitive advantage than on student-athlete welfare at the institutions that could afford to provide the allowance. For example, Southern Louisiana University suggested that the rule would only benefit the "haves and would widen the chasm between BCS schools and non BCS schools" (Dennie, 2011, p. 10). East Tennessee State University added that the expense allowance would create an "arms race effect at a time of economic hardship when many institutions are facing budget cuts across campus" (Dennie, 2011, p. 6). Tennessee Technological University even went as far as suggesting that the allowance amounted to "tattoo money", which presumably meant that student-athletes' needs for the additional aid will be used to purchase frivolous items or services like personal tattoos. Further, some Ivy League institutions (i.e., Harvard, Cornell), which do not even offer athletic scholarships, voted in support of the override (Dennie, 2011).

In light of many of these concerns, the NCAA Board of Directors did suspend the legislation and vowed to revisit the potential to meet this very real shortcoming for student-athletes through a future piece of legislation that was attentive to the feedback they received from the membership. In our opinion, when assessed against our proposed College Athletics Ethical Leadership Continuum, those voting in favor of the override clearly failed to do the right thing for NCAA student-athletes at the schools that could clearly afford to pay for these additional miscellaneous expenses in a manner that is similar to other merit based scholarships on these same campuses. Further, we agree with University of Florida president, Bernie Machen, who was quoted as saying that it is "just embarrassing" that the increase in expenditures in intercollegiate athletics has primarily been funneled to increase coaches' salaries and improve and build facilities, and has yet to result in additional funding for student-athletes to meet their very real and actual costs of attending a university as a student (Staples, 2012). This funneling of funds away from student-athletes is a good example of how member institutions continue to placate several competing stakeholders at the expense of student-athletes, and clearly continue to preserve the status quo related to supporting and improving student-athlete well-being.

\section{NCAA Division III Cases}

Comparisons between Division I and III athletic programs commonly focus on economically related variables such as budgets, television contracts, licensing deals, and facilities, or the reality that athletically-related financial aid is allowable in Division I, and not allowable at Division III. However, although more subtle, an equally important difference between the divisions lies in the notion of "institutional autonomy". Although a manual of 284 pages is in place, in terms of important aspects of intercollegiate athletics such as admissions, academic standards, and eligibility requirements, Division III institutions are granted by membership the ability to establish many of their own individual standards and restrictions. In keeping with 
the notion that student-athletes at these institutions should be treated no differently than other members of the student body, in most instances student-athletes must simply be eligible to enroll and remain in good academic standing to participate. The institutional standards for the student body are the exact standards required for student-athletes, rather than a set of standards handed down from the NCAA. Discussions of drug testing and mandatory penalties for student-athletes who failed tests for street drugs provide one of many examples of Division III membership protecting vehemently the notion of institutional autonomy. A report published by the NCAA from the 2013 Presidents Council and Presidents Advisory Group meetings included the statement that the majority of institutions "echoed the sentiment of a shift towards an approach that allows for more institutional autonomy when possible" (Ohle \& Herzberger, 2013, p. 1). On the 40th anniversary of Division III, the NCAA's Champion Magazine described the ban on athletic scholarships and institutional autonomy as "the two defining characteristics of Division III" (Schwarb, 2014, p. 57).

Institutional autonomy is an aspect of Division III athletics that on the surface seems positive. The theory behind such decision-making freedom is that schools can and will do what is best for their student-athletes and their institutional missions and values. However, as Guilford College Sports Studies Professor Bob Malekoff points out, "The possible outcomes of institutional autonomy is that members would try to compete in ways that go against the 'academics first' mentality of the NCAA" (Childs, 2010, p. 1).

For example, some Division III institutions require only that a student be eligible to enroll to compete. No stipulation is in place which makes a student ineligible while on academic probation. This could mean that a freshman student-athlete in a spring semester sport could fail all of his/her classes in the fall semester and participate fully in the spring semester. The result is a student on academic probation, with no credits earned and a 0.0 grade point average being allowed to participate. Although this is perhaps an extreme example, and may not occur frequently, there are Division III schools which allow students to compete without restriction even when their grade point averages are below the minimum standard for graduation.

Examining certain realities of Division III athletics through the lens of our proposed College Athletics Ethical Leadership Continuum might indicate how some institutions choose to be competitive by doing things right, rather than doing the right thing. Foremost is the notion of the student-athlete as the primary stakeholder. We question the ethics of policy — or lack of a policy_which allows students who are not just struggling academically but failing academically to continue to participate fully in athletic competition. If indeed the success of the student-athlete is of primary in importance, then the time, effort, and focus required for athletics should be shifted to academic performance. Of course critics will point to research that supports the notion that membership on a team is predictive of retention and graduation, fearing that if a student-athlete is completely removed from a team he/she will leave the institution (Johnson, Wessel, \& Pierce, 2013/2014). We counter by suggesting that membership develop a system in which the student-athletes in question be allowed to maintain participation, but with agreed upon restrictions and academic support. It is our contention that if student-athletes are allowed to maintain their social grouping and return to competition when academic improvement is realized, these studentathletes will be more likely to stay enrolled and succeed academically. 
Lack of Progress-Toward-Degree Requirement. All student-athletes at the Division I level are subject to the NCAA's "Progress-Toward-Degree" legislation. This legislation mandates that to remain eligible for competition a student-athlete must earn six hours of credit toward a degree the preceding regular academic term to be eligible for the next regular academic term. In addition, student-athletes must complete $40 \%$ of the coursework required for a degree by the end of their second year, $60 \%$ by the end of their third year and $80 \%$ by the end of their fourth year (NCAA Division I Bylaw 14.4.3). Enacted in 2003, this legislation is intended to increase retention and graduation rates by ensuring that student-athletes take meaningful course loads, rather than four years of introductory or low level classes in an effort only to remain eligible.

At the Division III level the NCAA requirement is that student-athletes must be enrolled in a minimum full-time program of studies leading to a baccalaureate or equivalent degree and maintain satisfactory progress toward that degree (NCAA Division III Bylaws 14.01.2, 14.1.8.1, and 14.1.8.6.4). In many cases this means simply that the student-athlete be enrolled in a minimum of 12 credit hours. Where institutional autonomy comes into play is in the determination of how "satisfactory progress" is defined. In many instances as long as a student remains eligible to enroll for another semester, he or she is considered to be making satisfactory progress and is therefore deemed eligible for athletic competition. Often times the only standard required to be eligible to enroll is to maintain an established cumulative GPA. Some Division III institutions use a sliding scale of GPA to determine eligibility such as 1.6 for student-athletes with 0-23.99 credit hours, 1.8 for student-athletes with 24-53.99 credit hours, and 2.0 for student-athletes above 54 credit hours, while others require a 2.0 or higher regardless of total credit hours earned.

As troubling as participating in athletic competition with a 1.6 cumulative GPA may be, the possible unethical issue occurs due to the lack of a percentage of degree completion requirement based on years enrolled. Since Division III requires only that students be enrolled in 12 credit hours to compete, and not that they complete a percentage of a degree each year, it is possible for a student-athlete to enroll in 12 credit hours and then withdraw from any number of those credit hours after the end of the competitive season. At some institutions, for instance, as long as a football player enrolls in 12 credit hours at the beginning of the season, and does not drop below 12 credit hours during competition, he/she would be continually eligible to compete. Even if the player withdraws from six or more credits the day after the final game of a season, he/she has broken no rule and is eligible to compete the following season as long as his/her GPA remains in the accepted range. The end result of this cycle of withdrawing from classes to maintain the minimum GPA is student-athletes who have exhausted their athletic eligibility, yet due to numerous semesters in which a small number of credit hours were actually completed, the student-athlete may be semesters or even years away from completing a degree.

Critics might argue that the system in place is acceptable due to the notion that in Division III student-athletes are to be held to the same set of standards as the student body, and members of the student body are not required to meet progress toward degree standards. However, in terms of our proposed model, these critics fall prey to accepting the status quo and managing the present at the very least, and potentially failing to consider the student-athlete as the primary stakeholder. Member institutions must consider the outcomes for student-athletes who have 
exhausted their eligibility and yet remain semesters or years from graduating. If the institution is the primary stakeholder, this may be doing the right thing since tuition revenues continue to be paid by those students who are retained for additional semesters, but we question the ethics of allowing students to spend four or five years at an institution, amass considerable student-loan debt, and yet, end up not even relatively close to a degree.

Roster Sizes. Two realities give rise to the second dilemma to be discussed related to Division III athletics, that of roster sizes. First, again due primarily to the concept of institutional autonomy, in Division III there are no limits on roster sizes for athletic teams. Second, many small, private, Division III institutions are truly "tuition driven", meaning that a primary source of institutional revenue is generated by tuition dollars. This is in significant contrast to the Division I model wherein funding often comes from multiple sources.

In 2013, Methodist University, a Division III school in the USA South Conference boasted a 2013 football roster of 162 student-athletes. The average roster size of the four teams earning a birth into the National Semi-Finals in the 2013 season was 120. This figure does not include "freshman rosters" which in some cases add an additional 50 or more players to program totals. This is not an uncommon phenomenon across sports in Division III athletics. Baseball teams carry as many as 80 players, basketball teams may include 20 plus members, and sports like lacrosse and field hockey are also known to have what on the surface seem to be extreme roster sizes. Even with the inclusion of a Junior Varsity (JV) team and schedule, it seems difficult to imagine that all or even a high percentage of these athletes will receive meaningful playing time. Upon further consideration, the baseball roster size of 80 seems more egregious than even the football roster size of 160 . In football, with separate offensive and defensive units, two special teams units, and unlimited substitutions during play, it is easily conceivable that 60 players could see action in a given contest. Baseball however, includes only nine field players and more importantly limits substitutions (once a player leaves the line-up that player cannot return to action during that game), making it likely that on average 12-15 players will participate in any given game. As "the student-athlete experience" is central to the Division III philosophy, it seems incongruent to maintain teams of such size.

Of course the argument could be made that being a part of a team gives students a robust experience, as much has been written about the benefits of team membership. However, the relationship between playing time and retention and therefore graduation must be considered given the Division III emphasis on academic success. According to Johnson et al. (2013/2014), playing time was one variable which was found to be predictive of retention. In addition, the possibility exists that the existence of Varsity and JV designations might create an "us" and "them" environment within a given team. Some Division III institutions avoid academic designations such as "honors" and "advanced" in part to avoid this same "us" and "them" mentality among the student body.

Given the tuition-driven theme in place at many Division III schools, it seems that coaches and athletic departments are charged with, and perhaps pressured to, maintain large roster sizes to generate tuition revenue for their institutions. Philosophically, athletic departments have become institutional recruiting units working in conjunction with, and sometimes as adjuncts to, admissions departments. This 
analogy is even more salient considering at many Division III schools, the overall student body includes a high percentage of student athletes. On average studentathletes make up $19 \%$ of Division III undergraduate student bodies but numbers can reach 40-50\% (U.S. Department of Education, 2012). For example, data provided by the U.S. Department of Education (2012) identified the following percentages of undergraduate enrollments who participate on athletic teams at these Division III institutions: Averett University (VA) 43\%; Bethany College (WV) 51\%; Bluffton University $(\mathrm{OH})$ 46\%; Defiance College $(\mathrm{OH})$ 45\%; Huntingdon College (AL) 46\%; LaGrange College (GA) 40\%; US Merchant Marine Academy (NY) $47 \%$. In a higher education market place that is increasingly competitive in terms of attracting students, numerous institutions have added sports such as football with a primary goal of increasing admissions figures, and therefore tuition revenues.

The roster size issue has a history at the Division I level. Until 1973 the NCAA did not limit the number of scholarships that could be awarded by individual institutions. Essentially, schools could award as many scholarships as they could, or chose to, afford. Abuse of this open field of scholarship awarding was included in Gary Shaw's eye-opening book Meat on the Hoof: The Hidden World of Texas Football (1972). Before the limitations on scholarships-first in 1973, then 1978 and most recently 1992 - the University of Texas would use scholarships to stockpile athletes in the talent rich state of Texas and beyond. The strategy was based on the notion, for example, that not only would the University of Texas recruit and attract the state's best quarterback, but also the second, third, fourth, and fifth best quarterbacks, not because their coaching staff believed that all five could contribute, but so that their opponents in what was then the South West Conference would not have access to these players - thus essentially forcing schools like Texas A\&M, Baylor, and Houston to battle for the sixth, seventh, and eighth best players at the position. Although not the sole motivation, the scholarship limits were put into place for the sake of parity on the macro level, and for the fairness to the student-athletes being convinced to choose the University of Texas when in reality there was never a chance for them to actually play. Of course coaches and administrators denied this as a recruiting plan, but it became increasingly clear that with roster sizes of 100 or more (the 1972 team included 110 student-athletes), only a small percentage of the student-athletes would ever compete in any meaningful way.

Interestingly, NCAA membership places roster size limitations on teams competing in postseason play. Although this is largely a cost containment issue, such limits make clear the idea that smaller numbers of players are necessary to play the game at the highest level. In football, for instance, a team qualifying for playoff competition is allowed only 58 players on its roster. Clearly the NCAA and member institutions go to great lengths to ensure the highest level of play in each division. Apparently a 58-player roster is sufficient to reach this goal. In other words, even considering economic implications, if the NCAA membership believed that more than 58 players were necessary to put the best product on the field, playoff roster size limitations would be increased accordingly.

This is not to say we believe a scholarship at Division I or a roster spot at Division III should guarantee playing time, but recruiting players who have no realistic chance of playing seems unethical. Prima facie it appears that the practice of recruiting and bringing to campus so many student-athletes is being done for the purpose of revenue generation, rather than to provide real and meaningful athletic 
opportunities. Member institutions should consider whether they are doing the right thing by recruiting student-athletes who have little or no chance of actually "seeing the field". More critically, are the student-athletes in question being sold a "bill of goods" that is misleading and unjust?

NCAA President Mark Emmert recently stated that, "We have a responsibility to provide student-athletes with the opportunity to compete in a principled, honest environment, regardless of the division or resource level" (Emmert, 2014, p. 5). The membership needs to consider whether it is operating in a principled and honest manner when it comes to roster sizes and the realities of tuition-driven institutions. Again considering the tenets of the proposed College Athletics Ethical Continuum, it does not seem clear that the student-athlete is the primary stakeholder. Do extreme roster sizes reflect this principled and honest environment called for by Emmert? Or is this again a case of the institution being the prioritized stakeholder, and perhaps doing the wrong thing right?

Both cases described herein demonstrate a trend on behalf of membership institutions to manage the present rather than selectively abandoning strategic ways of the past to manage the future. Division III institutions, in the current competitive and economically difficult era manage athletic programs to increase tuition revenue. As was pointed out, this model results in athletic departments acting like arms of the admissions office rather than student-centered departments intended to create equitable, engaging, and beneficial experiences for all students.

Continually allowing student-athletes to enroll and compete in the absence of meaningful progression toward graduation is not in the best interest of the studentathletes, particularly considering the escalating amounts of student loan debt many student-athletes amass. Similarly, maintaining rosters beyond which meaningful playing time is possible gives some student-athletes unrealistic expectations and sets them up for disappointment and feelings of failure. Although our focus is the student-athlete as primary stakeholder, the institution's perspective deserves attention here as well. Considering the importance of data related to retention and graduation rates (Johnson et al., 2013/2014), it seems apparent that an institution would benefit from the proposed changes. It seems intuitive that student-athletes who make continuous progress toward a degree, and who have quality athletic experiences, are more likely to remain enrolled and graduate. In the end, the motivation to maintain the current system is clear. The status quo generates higher levels of tuition revenue for Division III institutions in a competitive higher education marketplace. However, the current system does not adequately take into consideration the long-term wellbeing and academic success of many student-athletes.

\section{Conclusions}

Utilizing the proposed College Athletics Ethical Leadership Continuum as a lens, it seems clear that instances exist in which NCAA member institutions, by virtue of their role in interpretation and sanctioning the NCAA itself, could work to create an environment in which student-athletes are the primary stakeholder. That is, we suggest that college athletics leaders should continually provide a critical consideration of the present and demonstrate leadership for innovation, growth and the future. The four cases presented provide examples of policies, practices, and bylaws that potentially fail to promote the principled and honest environment 
called for by the NCAA's President (Emmert, 2014). We believe that obvious and clear cut examples of cheating and rule breaking are addressed appropriately by the NCAA and member institutions, but the cases herein expose the existence of a gray area between doing things right and doing the right thing. This gray area is dynamic rather than constant and requires careful and at times difficult consideration of key outcomes for student-athletes. Again, under consideration here are not those examples of obvious wrong-doing, but the more subtle interpretations of existing regulations - those cases when a clear moral minimum may be difficult to establish.

We acknowledge that our proposal of a higher moral minimum that insures that we do things right for our student-athletes first and foremost can come at a cost. Although the cost in question may come in different forms depending on the NCAA division, it is clear that creating an environment in which student-athletes are the primary athletic stakeholders requires critical analysis and a reallocation of resources, both human and financial. For example, Division III institutions could face potential decreases in tuition revenue, by either adopting our proposed position that would require meaningful progress toward degree legislation, and by reining in roster sizes. We understand and appreciate the implications of losses and further realize that additional programming or savings would be needed to recover this lost revenue. An example for these compromised Division III institutions might be adding additional sports, adding new and attractive academic programs, or increasing student activity offerings to attract new students to replace those lost as a result of these proposals. At Division I institutions, that regularly offer both head and assistant coaches multiyear contracts worth millions of dollars in several revenue and nonrevenue sports, there is absolutely no excuse for not reallocating some of these same long-term financial commitments toward student-athletes. At the very least, these schools should award full cost of attendance scholarships for a full five years as the minimum award to athletes on a full grant in aid, and a percentage of this amount to those on partial scholarships.

In addition, it should be noted that we do not intend to say that all NCAA rules are unethical and that all NCAA members fail to do the right thing when developing and enforcing the rules. Obviously, the membership has in place numerous rules, restrictions, and standards which are beneficial to the welfare and academic success of student-athletes, and are thus already reaching the proposed higher moral minimal necessary to provide true ethical leadership in college sports. However, we also feel that in several critical areas, such as the situations reviewed in our case presentations, the moral minimum in which several NCAA members are acting on is just too low and we are stuck with a present that is determined to just do the wrong things right.

We believe there are several additional cases that could be examined through the lens of the College Athletics Ethical Leadership Continuum to better understand if current policies and behaviors meet a higher moral minimum and the right thing to $d o$ standard. These analyses can include the assessment of such issues as institutional autonomy, coach and administrator salaries, initial eligibility standards, drug testing policies, university admissions for student-athletes, academic support services, media rights contracts, game scheduling and start times, student-athlete transportation, and potentially even the role of faculty in the governance process of college athletics.

In conclusion, through this commentary we have advanced a College Athletics Ethical Leadership Continuum, which we feel can be used to assess the behaviors, rules, and decisions made by NCAA membership. A fundamental principle of this 
conceptual model includes holding the student-athlete as the primary stakeholder of college sports activities, a standard easily justified given the core values and mission of the NCAA. Analyses of four specific issues currently challenging the well-being, success, and development of student-athletes were used to provide a critical analysis of the present to suggest more enlightened decision making for the future. Our analyses and conclusions for the four cases we chose to focus on indicated that the NCAA membership has compromised the wellbeing and academic success of student-athletes.

\section{References}

Armstrong, A., \& Muenjohn, N. (2008). The ethical dimension in transformational leadership. Journal of Business Systems. Governance and Ethics, 3(3), 21-35.

Associated Press. (2011). Schools object to scholarship plan. ESPN College Sports. Retrieved from http://espn.go.com/college-sports/story/_/id/7392725/schools-objectncaa- multiyear-scholarship-plan

Bennis, W.G., \& Nanus, B. (1985). Leaders. New York, NY: Harper \& Row.

Bennis, W.G. (1989). On becoming a leader. New York, NY: Addison Wesley.

Campbell, E. (1992). Personal morals and organizational ethics: How teachers and principals cope with conflicting values in the context of school cultures. (Unpublished doctoral dissertation). University of Toronto, Canada.

Campbell, E. (1997). Ethical school leadership: Problems of an elusive role. Journal of School Leadership, 7(3), 287-300.

Childs, P. (2010). Division III prepares to track athlete graduation rates. The Guilfordian. Retrieved from http://www.guilfordian.com/archives/2010/03/26/division-iii-preparesto- track-athlete-graduation-rates/\#sthash.KcyLWiZR.dpuf

Davis, T., \& Hairston, C.T. (2013). NCAA deregulation and reform: A radical shift of governance philosophy? Oregon Law Review, 92, 77-128.

Dent, M. (May 19, 2013). Colleges, universities slow to offer multiyear athletic scholarships. Pittsburg Post-Gazette. Retrieved from http://www.postgazette.com/ sports/ Pitt/2013/05/19/ Colleges-universities-slow-to-offer-multiyear-athletic-scholarships/ stories/20130519

Dennie, C. (December 15, 2011). A list of override requests. College Sports Law Blog. Retrieved from http://www.bgsfirm.com/images/stories/2k_overrides.pdf

Eddy, P.L. (2010). Community College Leadership: A Multidimensional Model for Leading Change. Sterling, VA: Stylus Publishing.

Emmert, M. (2014). Staying grounded in the core values. NCAA Champion, 7(1), 5.

Garza Mitchell, R.I. (2012). Doing the right thing: Ethical leadership and decision making. New Directions for Community Colleges, 159, 63-72. doi:10.1002/cc.20027

Gillen, D. (2012). Doing the right thing versus doing things right. Air Force Print News Today, Retrieved from http://www.au.af.mil/au/awc/awcgate/af/doing-right-thing.htm

Gough, R. (1994). NCAA policy's strangling effect on ethics. Record, 3-5.

Groves, K.S., \& LaRocca, M.A. (2011). An empirical study of leader ethical values, transformational and transactional leadership, and follower attitudes toward corporate social responsibility. Journal of Business Ethics, 103, 511-528. doi:10.1007/s10551011-0877-y

Hosick, M.B. (February 17, 2012). Multiyear scholarship rule narrowly upheld. NCAA.org. Retrieved from http://www.ncaa.org/about/resources/media-center/news/multiyearscholarship-rule-narrowly-upheld

Johnson, J.E., Wessel, R.D., \& Pierce, D.A. (2013/2014). The influence of select demographic, academic, and athletic variables on the retention of student-athletes. Journal of Student Retention: Research. Theory into Practice, 15, 135-155. 
Kant, I., \& Paton, H.J. (2009). Groundwork of the metaphysic of morals. Scranton, PA: Harper Perennial Modern Classics.

Kanungo, R. (2001). Ethical values of transactional and transformational leaders. Canadian Journal of Administrative Sciences, 18, 257-265. doi:10.1111/j.1936-4490.2001. tb00261.x

Kihl, L. (2007). Moral codes, moral tensions and hiding behind the rules: A snapshot of athletic administrators' practical morality. Sport Management Review, 10, 279-305. doi:10.1016/S1441-3523(07)70015-3

Kvalnes, O., \& Hemmestad, L. (2010). Loophole ethics in sport. Nordic Journal of Applied Ethics, 4, 57-67.

Mahoney, D. (2006). Ethics and the school administrator: Balancing today's complex issues. Lanham, MD: Rowman \& Littlefield.

Michael, M.L. (2006). Business ethics: Law of rules. Business Ethics Quarterly, 16, 475-504. doi:10.5840/beq200616445

National Collegiate Athletic Association. (January 2, 2013). Breakdown of Division I rules changes. NCAA.org. Retrieved from http://fs.ncaa.org/Docs/NCAANewsArchive/2013/ january/breakdown $\% 2 \mathrm{Bof} \% 2 \mathrm{Bdivision} \% 2 \mathrm{Bi} \% 2 \mathrm{Brules} \% 2 \mathrm{Bchangesdf} 30 \mathrm{html}$

National Collegiate Athletic Association. (2013, August 1). 2013-2014 Division I Manual: Operating Manual. Retrieved from http://www.ncaapublications.com/p-4324-20132014- ncaa-division-i-manual.aspx

National Collegiate Athletic Association. (2013, August 1). 2013-2014 Division III Manual: Operating Manual. Retrieved from http://www.ncaapublications.com/p-4324-20132014- ncaa-division-ii-manual.aspx

National Collegiate Athletic Association. (2014a). NCAA Core Purpose and Values. Retrieved from http://www.ncaa.org/about/ncaa-core-purpose-and-values

National Collegiate Athletic Association. (2014b). About. Office of the President. Retrieved from: http://www.ncaa.org/about/who-we-are/office-president

Ohle, J., \& Herzberger, S. (2013). Division III Presidential Quarterly Update: August 2013.http:// www.ncaa.org/sites/default/files/Presidents_Quarterly_Update_August-27_2013.pdf

Preskill, S., \& Brookfield, S.D. (2009). Learning as a Way of Leading: Lessons From the Struggle for Social Justice. San Francisco, CA: Jossey-Bass.

Schwarb, A.W. (2014). Blood, sweat and forty years. NCAA Champion, 7(1), 54-62.

Segrest, D. (2011). College athletes' rights: Some athletes lose their single-year scholarships to better players. The Birmingham News, Retrieved from http://www.al.com/ sports/ index.ssf/2011/10/college_athletes_rights_some_a.html

Sergiovanni, T.J. (1992). Moral Leadership: Getting to the Heart of School Improvement. San Francisco, CA: Jossey-Bass.

Shapiro, J.P., \& Stefkovich, J.A. (2005). Ethical Leadership and Decision Making in Education: Applying Theoretical Perspectives to Complex Dilemmas. Mahwah, NJ: Lawrence Erlbaum.

Shaw, G. (1972). Meat on the Hoof: The Hidden World of Texas Football. New York, NY: St. Martin's Press.

Staples, A. (2012). Full-cost-of-attendance scholarship debate could break up FBS. Sports Illustrated. Retrieved from http://sportsillustrated.cnn.com/2012/writers/andy_staples /03/08/presidents-scholarships/

Starratt, R.J. (2004). Ethical Leadership. San Francisco: Jossey-Bass.

Staff, T.S.N.C.A. (2008). Avery's antics sparks NHL to make new rule. TSN. Retrieved from http://www.tsn.ca/nhl/story/?id=234281

United States Department of Education. (2012). Equity in Athletics Data Analysis Cutting Tool. Retrieved from http://ope.ed.gov/athletics/Index.aspx

Wolverton, B. (February 22, 2013). Who opposed multiyear athletics aid? You might be surprised. Chronicle of Higher Education. Retrieved from http://chronicle.com/blogs/ players/who- opposed-multiyear-athletics-aid-you-might-be-surprised/29639 